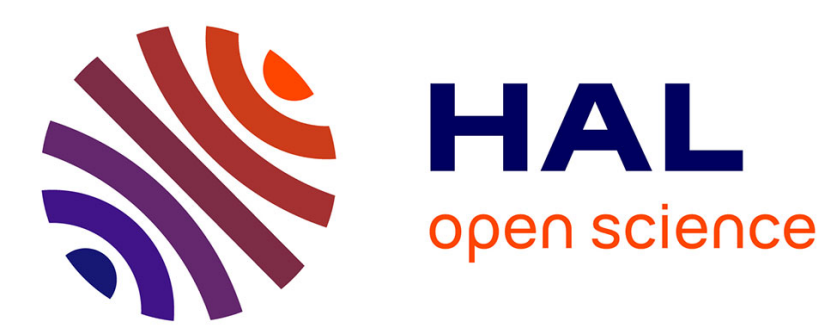

\title{
Determining the Determined State: A Sizing of Size from Aside/the Amassing of Mass by a Mass
}

\author{
Marvin Kirsh
}

\section{To cite this version:}

Marvin Kirsh. Determining the Determined State: A Sizing of Size from Aside/the Amassing of Mass by a Mass: The Determined State. Philosophical Papers and Review, 2013, 4 (4), pp.49-65. 10.5897/PPR12.026 . hal-00875392

\section{HAL Id: hal-00875392 https://hal.science/hal-00875392}

Submitted on 22 Oct 2013

HAL is a multi-disciplinary open access archive for the deposit and dissemination of scientific research documents, whether they are published or not. The documents may come from teaching and research institutions in France or abroad, or from public or private research centers.
L'archive ouverte pluridisciplinaire HAL, est destinée au dépôt et à la diffusion de documents scientifiques de niveau recherche, publiés ou non, émanant des établissements d'enseignement et de recherche français ou étrangers, des laboratoires publics ou privés. 


\title{
Determining the determined state: A sizing of size from aside/the amassing of mass by a mass
}

\author{
Marvin E. Kirsh \\ California State University, Los Angeles, Department of Anthropology, USA.
}

Accepted 8 March, 2013

\begin{abstract}
A philosophical exploration is presented that considers entities such as atoms, electrons, protons, reasoned (in existing physics theories) by induction, to be other than universal building blocks, but artifacts of a sociological struggle that in elemental description is identical with that of all processes of matter and energy. In a universal context both men and materials, when stressed, struggle to accomplish/maintain the free state. The space occupied by cognition, inferred to be the result of the inequality of spaces, is an integral component of both processes and process interpretation; arbitration space, ubiquitous throughout nature, occurred to a vast number of vastnesses, a manifestation of the existence of time dependent mass/number/amount, is argued to be located to the same judging criteria with which principles are determined for sociological purposes: the processes of mind are determined (excuse the pun) to occur as a free state that is reflectively equal to what is construed by the intellect as universe. Scientifically determined states are not free states.
\end{abstract}

Key words: mind matter form and energy, observation interpretation and common causes, the concept and physical parallels, sociological and scientific process, legality arbitration and nature, social equality and mathematical inequality, the transcendental object.

\section{INTRODUCTION}

I Know Why The Caged Bird Sings

The free bird leaps

on the back of the wind

and floats downstream

till the current ends

and dips his wings

in the orange sun rays

and dares to claim the sky.

But a bird that stalks

down his narrow cage

can seldom see through

his bars of rage

his wings are clipped and

his feet are tied

so he opens his throat to sing....

Maya Angelou (2009)

From within a surrounding cosmos, vast in proportion to the self, surfacing from observation, measurement, experiment and experience from the known dawn of ideas is question concerning the nature of time, fate and determination related to choice and path, cage and contents; in analogy to the modern study of determined form from undifferentiated stem cells it can be asked whether men and earth are determined products whittled from a more potent, grander, eternal vastness of a free(er) nature; whether processes of containment are the consequence of size disparity or of, a more relative, disparity of amount/mass that is independent of absolutes, direction from vast to small, visa-versa.

In order to organize and reduce modernly uncontained ideas about the self, in this presentation it is considered that science method and modern technology endeavor an unequal work of the self, of itself, with the states of nature from which the self logically descends. Technological creation relies on science theory and method that divides nature into structured nature into structured orders,

E-mail: kirsh2152000@yahoo.com, mkirsh@calstatela.edu. 
hence determined states (Gould, 1981). Is employed for the construction of models of nature are centered on learning from controlled motion, universal states relying on dualisms, to describe relations of energy, time, matter to capture to the intellect explanation centered rationally on the symmetry of the circle, subsequently fitted and refitted to the same notions possessing the same gap in explanation, beginning and resulting quirks, indeterminacies, predictabilities and un-predictabilities of a nature that inexplicably rolls along without a witnessible beginning or end. Scientific renditions of the elements of nature realize electrons, protons, atoms, granted freedoms based on probability distributions evolved from the application of a rational objectivity that not only disregards the behaving self but seeks to capture it to empirical rendition with these same premises that are evolved from the imagination and inductive reasoning. The same structuring root logic employed to confer standard definitions for analyses fails to draw a possible meaning of modeled determined states as they are related to the mutual frustrations of both human beings and materials for freedom, hence for the freedoms of human beings alone if creations bridging the imagination and the empirical world can be claimed to be reflected inclusively from perceptual experience; if all creative notions are argued to originate from perceptual experience they can be argued to be contained by it.

\section{MATERIALS AND METHODS}

The 3-D graphs of natural forms were generated using Calc 3-D Pro, constructed by Andreas Greuer, available free at http:// www.calc.3d.com.

Materials employed include personal notes and coursework undertaken while pursuing graduate study in biochemistry, later in philosophy and anthropology. Though they are not essentially elaborated from (with the exception of Einstein's equation $E=m c^{\wedge} 2$ ), in retrospect, the results presented here are framed well with the writings of Albert Einstein (Einstein, 1905), Mary Hesse (Brown et. al., 1996), Paul Feyerabend (Feyerabend, 1975), Karl Popper and Thomas Kuhn (Hutcheon et. al., 1995) concerning the theory, methods and sociology of science. Feyerabend felt that scientists with interpretation from original perspectives suffered political oppression; he described a political like social force opposing new theory that was different to accepted notions winning the affirmation of test. In this respect, if nature is seen to consist of stochastic processes, atoms and molecules in a state of anarchy that become determined to various states, inference from analogy suggests that the anarchic state is the free state from which determined social and natural states are derived, science theory and method, hence application, becoming dehumanized in allegory to oppressive political forces that resist anarchy as it is perceived to represent human freedom. More recently Hesse has offered the assessment that science bridges problems by analogy; if waves can be propagated by water then it can be asked if light waves are propagated by a medium, designated as the luminiferous ether. In analogy (excuse the pun but Hesse is apparently correct), the views of Hesse and Feyerabond can be interpreted to mean that 'analogy' makes for politically originating oppression arising from becoming determined states upon becoming open conceptual states, refers to question what constitutes the free state: analogy of method -byanalogy to method establishing randomness as freeness infers that other than the random state, 'the analogy' itself constitutes the free state that can be the victim of oppression. Defining 'the analogy' as the free state infers that it has physical characteristics if it is the consequence of comparison of states, one of which (randomness) is physical in nature. Kuhn in the early 1900's further questions the role of ideology to define a science process that proceeds erratically in which validity of theory is judged in terms of verisimilitude, truthful appearances, at the same time that Karl Popper expressed belief that theories must be falsifiable to be acceptable, while Feyerabend argues that few propositions would be falsifiable. At the fringe of conjectures and theory, ideology, or of ordinary common sense, is an outer margin of the small, vast that is beyond witness and has been falsely placed by projection into the same context as the scientist, citizen, either wanting freedom from tyranny or from tyrannical natural law. A novel perspective to the orientation of the nature of mind and matter will be presented; it might be feasible to assume, at all perspectives, internal, and/or external, that both outer and inner margins are always in physical motion, engaged in relative motion if either bears physical properties and can be joined by analogy, either that the proposed analogy is neutral-i.e. analogy cannot be made between the self and it's witnessed environment and an unwitnessible outer realm. Introduction of theory by Albert Einstein concerning the nature of light, proposing that matter and energy are inter-convertible, makes visible (excuse the pun) a potential analogy of mind and matter though it is difficult to fit to interpretation if the velocity of light is constant and not relative, or if any facets of interpretation can assume a comparison-defeating value of zero-i.e. the zero gravitation state of general relativity theory.

It is thus the method of research for this presentation to begin with logical contest to the notion of a constant velocity of light, to construct and to proceed with the employment of "the analogy" as the unit of construction, oppression is 'dehumanizing' in the sense that it is unnatural when visualized as an oppression to 'the analogy' or 'the concept' rather than upon the individual for his specific ideas or upon scientific contest for ideas and evidence with which to verify existences. Ingold (Ingold, 1993) in anthropological theory for the study of material culture from artifacts of the past, describes a real world of contexts in which nothing is still, landscape, and the tasks and activities of men, taskscape, in motion made in analogy to an orchestrated musical composition: unification and division of men and nature is only accomplishable with description entailing contiguity that is both physical and temporal. Homeostasis, generally used to describe kinetic balances in stochastic systems, finds difficult analogy in social systems. . Presented here, in terms of function that ubiquitously cannot not refer to structure, visa versa, though each with minds of their own, , is intersecting and dynamic distance containing distance, able to form designs that are atemporal in nature and yet can bear time and motion. e.g. the graphical shapes in the Figures, analogy is difficult to achieve between matters that are necessarily in motion that appears to have confining balances, scientific explanation for the means of containing matter to form is not available from inductive reasoning involving unwitnessible forces holding matter together, they do not account for action and reaction, or potential forces that oppose tangible structure. In the presented view the law of action and reaction is inferred to encompass the entire in which the vast assortment of entities/parts contained to it are postulated to move directionally in alignment with (a) preceding action(s), to progress directionally and obtaining a greatest life time. Analogy regarding homeostasis is simultaneously confined to a whole that is contained to the unwitnessible concept 'universe' that contains the intersection of energy with tangible physical form, either neither determined nor anarchic, egg stem cells as well as the cells of differentiated tissues in this model are all in a state of directional motion that by analogy is very old, related to prior impulse that is responsible for the perception of kinetic homeostasis, here discussed to emerge strictly from (natural, sociological or political) arbitration processes in which 
the free state is a non-anarchaic 'universe'.

\section{RESULTS}

Current scientific models when exposed to criteria employed in philosophical discourse involving the imagination, induction, validity, and coherency, the senses and the nature of knowledge, anthropological discourse paralleling the natural and social sciences, evolution and culture, a lack of awareness of the physical/natural scientist to the subjectivity of his work is revealed; misunderstanding involving a relativeness embodied to the cosmos, existence of natural constants, the nature of number and emergence, an inability to capture mind and matter to congruent constituents, and a struggle to capture description to universal terms are entailed. It is hypothesized that interpretation has been made to be overcomplicated, involves perplexity surrounding number, infinity and zero, an innate imitation facility that bears confused discrimination of action and reaction, transference and counter-transference, and is suggested to be the consequence of problems resided historically to chronic external material influences on the environment.

\section{DISCUSSION}

If in the act of arbitration of whatever topics arise to created discourses, men/women are claimed to be actors that mimic and learn by mimicking, then litigation/ arbitration behavior, described as effort expended to resolve conflict, might be taken from its' sociological context to elaborate a view that the elements of natural processes also find direction from acts of arbitration that result in the taken courses of processes; humans learn legatorial behavior from proximal experience with nature and secondly apply the determined states inferred from direct perception to science models with hope to find bail from a prison of frustrations with nature. Description coining the term "man verses nature" to describe both scientific and sociological processes, in proceedings that test the always becoming struggle at the interface of science, society, and the individual, have come to establish sovereignties of each in a setting underlined with thoughts of conservation of energy, rather than momentum; impulse based scientific test and invention are judged with respect to appearing truthfulness, verisimilitude, centered on criteria of energy exchange applied to, the miniscule in comparison, path of human impulse tested entities, to warrant applications in communities, if not on a global level.

It might not be improbable that a greed for resources extending from an occluded greed of nature for assets threatened by impulse(s) indigenous to unknown spaces, other than motivating creative originality arisen from within the self, might otherwise be reflected from struggling arbitration mechanisms of a pathology bearing nature and the partly occluded topic of a natural imitation facility bound to learning and behavioral facilities, being lead to act accordingly to result in a self-deceit founded mathematics of the natural state formed by counting from a non-existent zero to an endless infinity in which the theorizer/experimenter/observer is invisibly hidden within models that stumble conceptually at the unequal interface of self/nature and self-as-nature/nature. The analytical complexities of a simultaneity of processes within their observed setting, the equalities and spontaneities of 'seeing' have been subsequently transformed to a method in science pursuits employing in interpretation, from observation to proclaimed cause, dynamic/time dependent description given a fixed status on the planar surface of writing paper; time elapsed within the interval of observation, a period of lasting reconsideration potential played among the symbols and forms inherent to cognition, seemingly made naturally so to the senses and perceptions should not exclude the arbitrating, impulse armed hand of observation; in a correctly captured universe, arbitration from witness makes record of contrasts that are both producer and product of inequality rather than equality.

The expression of ordinary physical law on the flat plane of paper is capable only to make expression in terms of the atemporal simultaneity of common cause and witness engagement; a temporal lapse is postulated to exist ubiquitously, internally, within the mind, externally, between kinetic and potential energy in which mass values are time dependent; only partially elastic collisions can be postulated to exist under conditions of action at a distance between causes and witness that is supposed inelastic in nature, e. g. a universe where only momentum is witnessed to be conserved.

In the following example of a cow kicking simultaneously two balls, change occurred from within, considered in definition to be axiomatic and universal to all real description, a perspective considered necessary for real fields of observation, affixed to the acute angle between possessed momentum and direction of motion, confined to the single first perspective, limited not to endeavor description involving the motionless state, is always engaged in witness/cause-associated motion regardless of the forces and parameters of imparting energies; it is extended to accommodate contingency rather than cause and effect, and, in contrast to some modern ideations, to objects of nature that are in obligatory motion, i. e. to all objects. An observer witnessing at a distance, for instance, physical change produced by the event of a cow kicking, in a single motion, two objects at rest, such as balls 1 and 2, might seek to determine a common cause if reconsideration and intuition suggest that one might exist. If mass is assumed, for the purpose of example, to be independent of time, if the frame of analysis is contained to include together the cows kick and the impacted balls, distance becomes independent of time in analysis framed, as is ubiquitously necessary for all meaningful observation, with respect to the necessity 
and determination of common cause; i. e. process description is contained to the generation of form from a path of motion from a path of motion.

Consider the Law of Conservation of Momentum in the following special, but plausible, case of a common system time and conserved distances involved in the example of the ball-kicking cow:

\section{Law of Conservation of Momentum (Wikipedia, 2012)}

$\mathrm{MV}($ impacting momentum $)=\mathrm{m} 1 \mathrm{v} 1+\mathrm{m} 2 \mathrm{v} 2+\mathrm{m} 3 \mathrm{v} 3 \ldots$ $=($ impacted momentum $)$ Equation 1

$1 \mathrm{a} \quad$ Mass

(Distance/Time)

$=\mathrm{m} 1 \mathrm{~d} 1 / \mathrm{t} 1+\mathrm{m} 2 \mathrm{~d} 2 / \mathrm{t} 2+\mathrm{m} 3 \mathrm{~d} 3 / \mathrm{t} 3 \ldots \ldots$.

If Time is defined $\mathrm{t} 1=\mathrm{t} 2=\mathrm{t} 3$ and Mass (ball 1 ) $=$ Mass (ball 2)

$1 b$ Mass Distance $=\operatorname{mass} 1 \mathrm{~d} 1+\operatorname{mass} 2 \mathrm{~d} 2+\operatorname{mass} 3 \mathrm{~d} 3$

In the cow kicking example:

1c $\Delta$ (Mass Distance) (Hoof) $=2 \Delta$ (Mass Distance) (Ball)

If $\Delta$ Distance (hoof) is defined $=\Delta$ Distance Ball $1=$ $\Delta$ Distance Ball2 (and $\mathrm{t} 1=\mathrm{t} 2$ ) (that is the event is viewed to be discrete, possessing a single common time):

$\Delta$ Mass (Hoof) $=2 \Delta$ Mass $($ Ball $)$

In analogy to a golf game in which the reach of the cow defines the dimensions of the playing area, if the law of action and reaction is applied the change in mass of the cows hoof would be its initial mass less twice the change in mass of a ball over a time interval equal to the time interval of motion of the balls, would had lost mass from the applied impulse. It is not necessary in this example to effect the condition of friction, gravity, or energy involvement of entities external to the cow and balls, to consider that the cow swings its' hoof at the balls a fixed distance to effect motion of the balls a fixed distance and to suffer a change in its' potential that can be visualized as $\Delta$ (Mass(Hoof) $\mathrm{V}$ (common) e.g. a common velocity (Distance/time) is assigned to the physical displacement of all components. The cow, in order to replenish lost potential consumes energy that is effected by existing causes that are common to all elements within the temporal range of the occurrence. The order of processes and energy changes is superfluous to a condition that can be visualized to be contained to the propagation of form; change in the example, related to both neurological and biochemical energy processes associated with the birth and history of the cow, kinetic energy release in the form of muscular motion, can be described within events in which a change in potential energy ubiquitously precedes motion/visible, changeassociated, kinetic energy release. It is not unfeasible that if the velocity of light is used to describe the potential energy of masses, that it is not only variable rather than constant, but subject to change that is associated historically with describable common causes of vast proportions in relation to the volumes and potential energy of processes acting over the period of observation from the first perspective of processes that are driven strictly by a delay between a change to potential that occurs in association with a change of state between energy/mass, and kinetic energy.

In analogy of the situation described in the example of the kicking cow to real nature, common system time and (approximate) common distances of motion of all elements exists when some energy in the final state is in the form of potential (i.e. Mass/ $\Delta$ Mass (hoof) or Mass/ $\Delta$ Mass (ball) rather than kinetic energy; the case $\Sigma$ impacting masses $=$ final mass is excluded not to exist, $\mathrm{i}$. e. a mass cannot move itself, nor might potential energy be numerically fixed to volumes of space within the temporal period of intercourses, but to the dynamics of, vaster in mass/volume, existing causes bearing time that is transposable directly to ordinary scales as easily as it is construed that though the change in mass of the discussed cows hoof is not concurrent with the motion that causes the balls to move, it is about the same kind of changes, of distance that is commensurate with the dimensions of the field of reference over a common time: the evidence of potential entails pre-existing potential for motion; motion preexisting motion. It is feasible to consider that real description is restricted to accounts of atemporal displacement in which time $(=t)$ from the third perspective has no coherent meaning assignable to the mutual frame of engaged agents. Description of a nature that is necessarily apriorily knowable to the senses, verses that of ideal states, laws, might not be contained to terms of action-reaction, time dependent expenditure of energy, but to the condition of energy matter conversion, possessing other than temporal description likened to the dynamics of a chemical or biochemical reaction, is mass or number density and proximity, historically emerged-emerging space, contained to potentially vast ratios: though also containing history process description entails disparities that are stable and commensurate with physical dimensions attached to the frame of witness and effect the spaces of existence.

In extrapolation from the inelastic association, all associations of $M=[M 1, M 2, M 3]$ necessarily preceded by both motion and potential for motion, must obey the same rule; in all cases motion, whether it precedes or follows events bears an acceleration to potential as if all components $M(1), M(2), M(3)$, heterogeneous (i.e. $M=M 1, M 2, M 3$ ) themselves are the products of associations/ collisions of entities of heterogeneous natures, are arbi-trated by nature. Arbitration by the author of the topic and parameters in the example, number of balls $=2, \mathrm{t} 1=\mathrm{t} 2=\mathrm{t} 3$, $\mathrm{d} 1=\mathrm{d} 2=\mathrm{d} 3$, Mass (ball 1) $=$ Mass (ball 2) so that facets of the described elastic collision bear similar parameters to the inelastic collision, is used to demonstrate the 
propagation of form and arbitration by nature in which witness engagement and potential for change occur over shared time intervals that may diverge parametrically after engagements, propagation of a trail in which a temporal lag separates kinetic energy and potential energy (e.g. the cow must accrue potential prior to kicking the ball) the distance of motion of all components is mechanically defined to all components so that it is describable in terms of an inelastic association involving joined objects in order to expose a historical importance to the nature of processes that are otherwise mostly elastic. The example situation is considered not to be plausible because of the relative size constraints imposed on the cow and balls with respect to the ratio (change in mass (hoof) $) /($ mass(hoof)). A cow might not move either a moon, or a bacterium by kicking it; the necessary propagation of form, criteria of (size, species) familiarity, is effected as a necessary containment of nature in order for associations to occur. The existence/conservation of energy bound to physical form, entails an appropriate likeness of dimensions and rates of motion, familiarity, in order for engagements; for an agent to engage two or more witnesses simultaneously with a single motion its' dimensions must be able to accommodate the distance to and between impacted objects; it is inferred that neither situation, $\mathrm{t}=0$ ( i.e. exact simultaneous contact by an agent with two other agents within the same motion), nor the entailed situation momentum $\mathrm{A}$ (time 1$)=$ momentum A(time2), exist in reality; though momentum is seen to be strictly conserved, mass and distance are seen to be relative when time is fixed as a common state variable to witness engagements. Actions of nature allowing associations, necessarily requiring recognition and familiarity for arbitrated engagement are associated with perceptively capable distances within the field of reference, preclude shortened lifetimes, large disparities in mass involving quick release of large quantities of energy, and might occur only under conditions of preexistence of the same, entail very short lived or no witness events to a universe that is witnessed to accrue substance and diversity: matter necessarily bears history/ time associated potential involving witness in pairs. The instance of inelasticity, potentially able to account for the energy of thought, the ether, entails its existence universally if the existence of potential is necessary to motion (e.g. the muscular motion of the cows hoof), visa versa (e,g. the change in potential of the cows hoof that proceeds the collision). In light of modern interpretation, Euclids' proposition of Ancient Greek times (Morrow, 1970) that division of the infinite line does not entail that it is infinitely divisible, does not necessarily entail the existence of atoms, protons, electrons, etc. but possibly a world of heterogeneous objects in motion that can undergo invisible change to their potential, visualized to effect with a delay, discrete change that is observed as an acceleration visible to the senses, the existence of change to observed structure, e. g. evolution/speciation, is brought about by motion/change-in-distance with time, mass that is time dependent. It might be asserted that the senses themselves, self, identity, uniqueness, the mind and objects of the external world are equally both consequent and effector of this same phenomenon. Description involving the existence of life here is held not to involve anabolism from catabolism but the emerged/ emerging appropriate places and spaces to the distribution of number (e.g. mass) over volume to render identity.

It is a perspective involving the reduction-absurdum assumption of identity of agents that both renders and resolves a paradox of the motion of bodies, involves a relocation of the angle between force of impact and direction of motion from obtuse in mathematical descriptions of the collision, to acute angles that are bound to perspectives existing at the receiving end of transmissions, to all engaged witnesses. In the above example the angle of impact between the cows hoof and the two balls is relevant only with respect to familiarity, parameters of distance that are involved in establishing the field of interaction, and are superfluous in the sense that interaction cannot occur without familiarity and proximity: within nature the inequality of reaction to action, counter-transference to transference, the product of arbitration, is the single appropriate example for description. George Devereau, a psychoanalyst who followed Freud, came to odds with him regarding the importance of transference and counter transference in psychoanalysis:

.....[Devereau] 'acknowledged Albert Einstein as his most important source of inspiration when he quoted the phrase: "we can only observe the phenomena that occur near or inside the experimental apparatus and the observer himself is the most important part of this apparatus". Devereux considered that he had gone further than Freud by suggesting that countertransference, rather than transference, was the central datum in the behavioural sciences. (Giami, 2001, p. 6).

In this analysis all angles can be seen to strictly relate force as a positive vector from the first perspective of the direction of motion, are acute; actions involving approach to loss of mass with a quick release of energy, a summation of angles descriptively approaching the infinite circumference of the circle, appear to be the only existing visible contradiction to the commonly accessible observation of the evolution of diversity in nature, suggest arbitration events that seek to confine/close and that are unlikely to occur freely in nature. The universal frame then might be described lingually only to indicate that it bears matter and energy in which all potential frames accumulate and transmit potential with time in an approximate linear fashion as if possessed with an appearing fixed velocity that is really a reflection of combination/recombination (e.g. Mass $\mathrm{N}$ involves the 
history of engaged inelastic associations each of MassN1 + MassN2 + MassN3 that comprise the history of MassN, so on for Mass(N1), Mass(N2).. etc.) under viable rather than decaying circumstances, Example is the product of familiarity enabled association involving mass/amount per volume and proximity, entail relatively uniformly accruing number (or mass); in analogy 'a (relatively) uniformly rolling mass gathers change, (relatively uniformly) rolling mass)'(see figure 1; linear velocity $\mathrm{V}$ in combination with congruent linear velocity $\Delta \mathrm{C}$ propagates various forms that are dependent on similarly congruent disparities that emerge from associations of entities that are vastly disparate (i.e. ( $\mathrm{MC}$ verses $\triangle \mathrm{MC}$ or singularly $\Delta \mathrm{M}$ if $\mathrm{C}$ is considered to be the product of $\mathrm{M}<<\Delta \mathrm{M})$ ). This description of nature is self containing; for any parameters $\Delta \mathrm{C}(\mathrm{a}), \mathrm{C}(\mathrm{b}), \Delta$ Mass(a), Mass(b) a form/shape is potentially describable to exist of parameters $\Delta \mathrm{C}(\mathrm{b}), \mathrm{C}(\mathrm{c})$, $\Delta$ Mass(b), Mass(c)...etc... bearing different distinct whole dimensions and composing number, familiarity for interaction ( $\mathrm{V}$ rather than $\Delta \mathrm{V}$ is reserved to indicate the familiar perspective); all possibilities are confined to possible forms of the type demonstrated in the figures. The set of all potential spaces are defined for their existence by a common time of interaction with regards to the attainment of discrete form.

From this perspective, reflected from the idea of common cause with which to understand nature, the minimal requirement for identity, construed as the ability to undergo change that is modulated from within a history of events, is a fairly steady rate of change with time, in analogy to a ball under the influence of gravity constrained to a slowly rather than quickly changing velocity while in free fall, is companioned with levels of potential energy that are dependent on its' history, place/location and the rate of fall within the particular interval of study. The rate of DNA mutation in living cells, as an example, might be expected to be linear with time, as DNA sequencing experiments on various species, tissues in fossil records suggest (Wells,2007, Fairbanks, 2010). All volumes of space both bear and effect motion, are identity possessing/unique; can be expected to both suffer and effect changes to the potential of states. The continual bearing of internally born diversity potential suggests that witness referencing the potential elements of root change, i. e. DNA mutation (Wikipedia on Gregor Mendel, 2012), expected as discussed to bear a linear rate of accumulation, might be expected to be conditional if some, but not all, existing motion is witnessible (Kirsh, 2012), the rate of growth of populations by reproduction demands a change with time to the potential of individuals/populations, conceptions/time/individual that is expected to be approximately fixed: a reality conjectured hidden to experience becomes reality that is hidden sometimes and not others depending on afforded and appropriate perspective. The ability to observe DNA and DNA mutation only with tools that amplify the abilities of the senses suggests a vast disparity, a vast physical distance of emergence between agents, the individual, cognition, the brain, and the molecular elements that compose it; parameters bearing inequalities that reflect congruencies rather than parallels/equalities are the only potential tools for understanding, e. g. DNA to cells, cells to brain/physiological structure, disparities of electrical/ physical impulse within the sequestration and alignment of form, may or may not be apparent or accessible to physical witness or test, of mind to matter.

Potential description might entail the inequality to be the parent of 'potential product(ion)', but 'parent' entails a temporal element, arbitration and inheritance, the inequality, not conceived to have a parent, alternately entails simultaneously the event, common cause, and the act of witness, all exchange. The two potential perspectives with which to head description, intercourses of dimensionless universal form verses energy kinetics and causation, are mutually exclusive. Discussion of the 'mechanics of enzymatic action of glucose dehydrogenase' and 'evolution of the mechanism of glucose dehydrogenase over the last 1000 years' are exactly distinct headings; the former is related to existing (atemporal) form, the latter to change. Attempts to associate form and change together in discussion can be expected to entail dissipating disparities of the kind witnessed to eventually intersecting non parallel trails, entailing the repetitive search for processes of a physical nature, particulars, to fill unknown intervening spaces; though potentially having similar ontologies, models that confuse form and functioning can birth only a psychical energy of contrast that, in analogy to the decay of mass discussed above in the example of the ball kicking cow, are dissipative with time. Concepts with which the world is divided for exploration should otherwise bear an eternal potential that transcends the identity of intercoursing agents, must refer to criteria of familiarity, that is, existence. It is possible to extrapolate, if some linear motions of nature that accrue change are conditionally witnessible and mutable in studies, upon the introduction of imposed change, emerged divides responsible to define what is vastly disparate to the senses are breached both within cognitive discriminations, and within nature, can produce various degrees of reciprocating aberrant potentials/behavior, shorter lifetimes to either (see below on the activities of corporation with respect to natural resources).

In the elastic collision, if initial velocities are known, final velocities in collisions are:

$\mathrm{V} 1=(\mathrm{m} 1-\mathrm{m} 2) /(\mathrm{m} 1+\mathrm{m} 2)(\mathrm{U} 1)+2 \mathrm{~m} 2 /(\mathrm{m} 1+\mathrm{m} 2) / \mathrm{U} 2$

$\mathrm{V} 2=(\mathrm{m} 2-\mathrm{m} 1)(\mathrm{m} 1+\mathrm{m} 2)(\mathrm{U} 2)+(2 \mathrm{~m} 1) /(\mathrm{m} 1+\mathrm{m} 2) / \mathrm{U} 1$ where $U=$ initial velocity, $V=$ final velocity. If $m 1>>m 2$ the final velocities reduce to: $\mathrm{V} 1=\mathrm{U} 1, \mathrm{~V} 2=2 \mathrm{U} 1-\mathrm{U} 2$

This is reminiscent of a possible situation using a variable velocity of light (Figure 1) in which $c>>v$, $(\mathrm{m} 1) \mathrm{c}>>(\mathrm{m} 2) \mathrm{v}$, if $\Delta \mathrm{c} \approx \mathrm{v}$ of engaged masses $\mathrm{m} 1, \mathrm{~m} 2$ over a shared time interval $m 1>>m 2$; disparities of $c$ (rather 


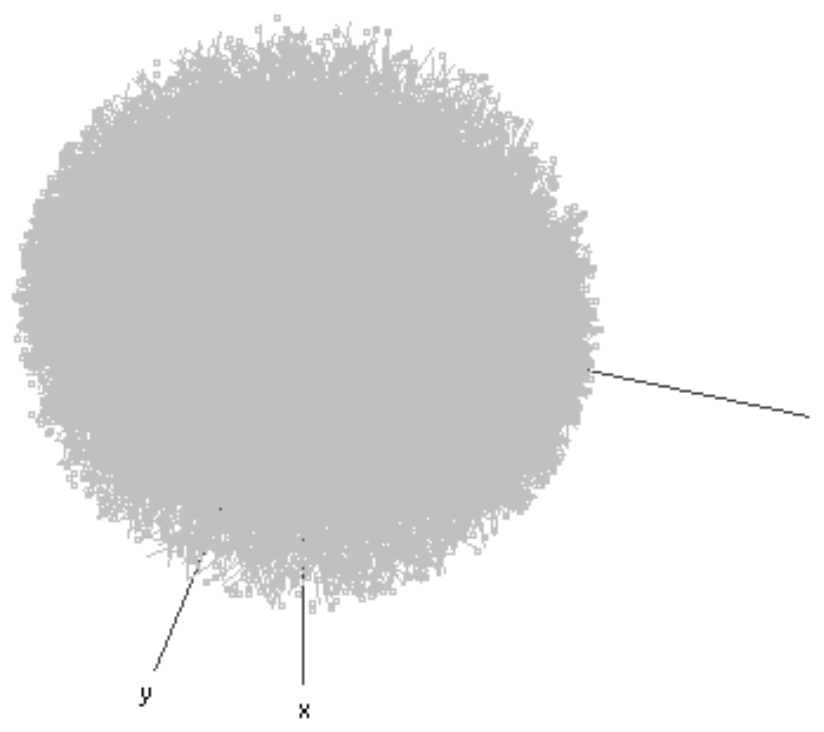

Figure 1a. The egg shape is a function of a variable C (Initial conceptions included absolute values (ABS) to ensure positive velocity values, show an unexpected effect on graph shapes, cause slight changes in angular orientation of blunt and pointed ends with respect to axis. A similar effect is seen with respect to different assortments of $n=0$ verses $n=1$ degrees of freedom to sine and cosine functions, or with respect to different numerical ratios of the four sine and cosine functions used in the expression for $R$.)

$E / m=\Delta V$ Slow Velocity^ $2 / 2+\Delta C$ Light Velocity^2

$\mathrm{V}=$ velocity of motion, $\mathrm{C}=$ Velocity of light (is applied as a variable)

$\mathrm{R}(\mathrm{a})$ Sin $@=\Delta$ Slow Velocity, $\mathrm{R}(\mathrm{a})$ Cos $@=\Delta$ Velocity of light

Radius(egg)/Radius(a) $=\left[[(\text { Sin theta })-(\text { Cos theta })]^{\wedge} 2+(\cos \right.$ theta $\left.)^{\wedge} 2+(\text { Cos phi })^{\wedge} 2\right]^{\wedge}(1 / 2)$

$10^{\wedge} 14<$ theta, phi $<10^{\wedge} 17$

$d($ theta, phi $)=\left(10^{\wedge} 17-10^{\wedge} 14\right) / 500=2.02 \times 10^{\wedge} 14$

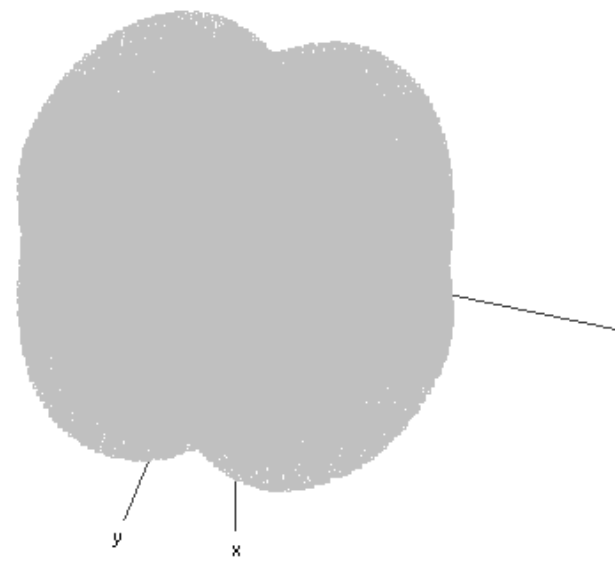

Figure 1b. An apple shape.

$\mathrm{R}=(\cos (\text { theta })-\sin (\text { theta }))^{\wedge} 2+\cos (\text { theta })^{\wedge} 2+$ $\left.\cos (\text { phi })^{\wedge} 2\right)^{\wedge}(1 / 2) 10^{\wedge} 14<$ theta, phi $<10^{\wedge} 17$ $\mathrm{d}($ theta, phi $)=\left(10^{\wedge} 17-10^{\wedge} 14\right) / 1000=10^{\wedge} 14$

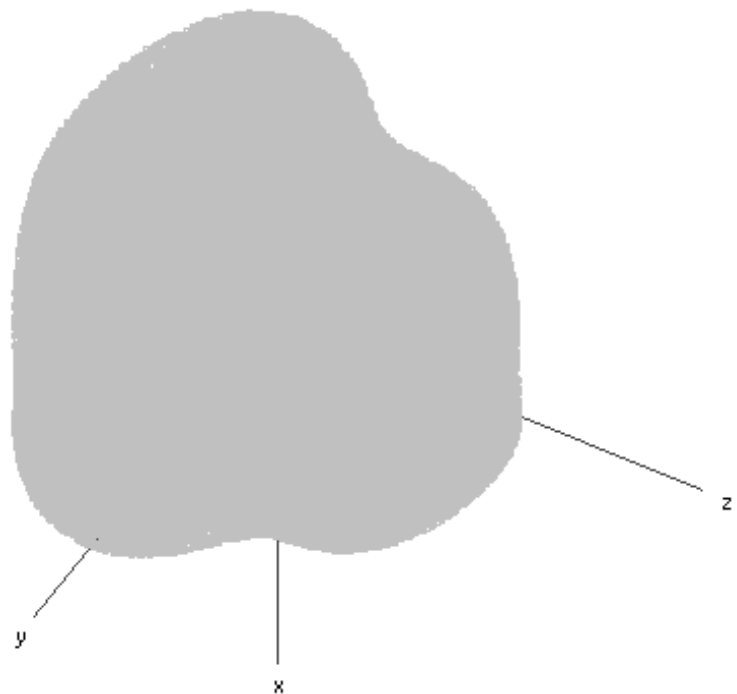

Figure 1c. A Pear shape

$R=\left[\left(A B S(\sin (\text { theta }))-2^{*} \cos (\text { theta })\right)^{\wedge} 2+\left(2^{*} \cos (\text { theta })^{\wedge} 2\right.\right.$ $\left.+\left(2^{\star} \cos (\text { phi })^{\wedge} 2\right]^{\wedge}(1 / 2)\right]^{\wedge}(0.5)$ $10^{\wedge} 14<$ theta, phi $<10^{\wedge} 17$ $\mathrm{d}$ (theta, phi) $\left(10^{\wedge} 17-10^{\wedge} 14\right) / 1000=10^{\wedge} 14$

than $\Delta \mathrm{c}$ ) to $\mathrm{v}$ reflecting potential limits, $\Delta \mathrm{c}, \mathrm{v}$ analogous with V1, V2. (From: Newton; $E$ (kinetic) $=m v^{\wedge} 2 / 2$, Einstein; $E($ potential $\left.)=m c^{\wedge} 2\right)$

$\Delta($ Energy $($ total $) / m)=\left(\mathrm{V}(\text { final })^{\wedge} 2-\mathrm{V}(\right.$ initial $\left.\left.) \wedge 2\right) / 2+\Delta \mathrm{C}^{\wedge} 2\right)$ 1

If a very large mass $M$ common cause is postulated to exist, bearing potential $E=M C^{\wedge} 2$, the creation of new potential $\Delta\left(\mathrm{mc}^{\wedge} 2\right)$ can be described:

$\Delta$ mass $=\Delta$ Etotal $/[($ velocity final^2-velocity initial^ 2$) / 2+$ $\Delta$ velocity light $\left.{ }^{\wedge} 2\right]$

$\Delta(\mathrm{m} / \mathrm{M})=\left[\left(\mathrm{Vfina}^{\wedge} 2\right) / 2-(\mathrm{V} \text { initial })^{\wedge} 22+\Delta \mathrm{C}^{\wedge} 2\right] /[(\mathrm{V}$ final $\left.)^{\wedge} 2 / 2-(v \text { initial })^{\wedge} 2 / 2+\Delta C^{\wedge} 2\right]$

If $\mathrm{M}>\mathrm{m}, \mathrm{m} 1 / \mathrm{M} \sim 0$ that is, $0=\sim\left[\mathrm{Vfinal}{ }^{\wedge} 2\right) / 2-(\mathrm{V} \text { initial })^{\wedge} 2 / 2$ $\left.+\Delta \mathrm{C}^{\wedge} 2\right]$

$\left(\right.$ Vfin $\left.{ }^{\wedge} 2\right)=(\text { Vinitial })^{\wedge} 2-2 \Delta C^{\wedge} 2$ or $1 \mathrm{c}$

$\left[\left(\mathrm{Vfin}^{\wedge} 2\right)=(\text { Vinitial })^{\wedge} 2-\left[\Delta \mathrm{C}(1)^{\wedge} 2+\Delta \mathrm{C}(2)^{\wedge} 2\right]\right.$ (see Equation 2c)

A 3D plot R, Theta, Phi $=\left[((\mathrm{n}+1) \mathrm{V}(\mathrm{x})+(\mathrm{m}+1) \Delta \mathrm{C}(\mathrm{x}))^{\wedge} 2+\right.$ $\left.\left.((\mathrm{m}+1) \Delta \mathrm{Cy})^{\wedge} 2\right)+((\mathrm{m}+1) \Delta \mathrm{Cz})^{\wedge} 2\right]^{\wedge}(.5)$, Theta, Phi] $\mathrm{n}, \mathrm{m}$ represent degrees of freedom for $\mathrm{V}, \mathrm{n}=0$, confined to (one) $x y$ plane), for $\mathrm{C}, \mathrm{m}=1$ confined to (two) $\mathrm{xy}$ and $\mathrm{xz}$ planes) reveals a closed appearing surface (e. g. apple, egg, pear shaped) depending on the generation of unique (rather than periodically repeating) sine and cosine values from large angular graphing periods $\left(\sim 10^{\wedge} 17\right.$ radians), divided into intervals (500 up to 4500 ) that 


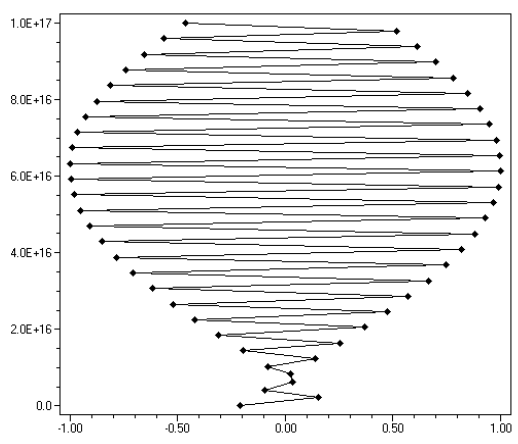

$d$ theta, $p h i=2.3088 \times 10^{\wedge} 15$

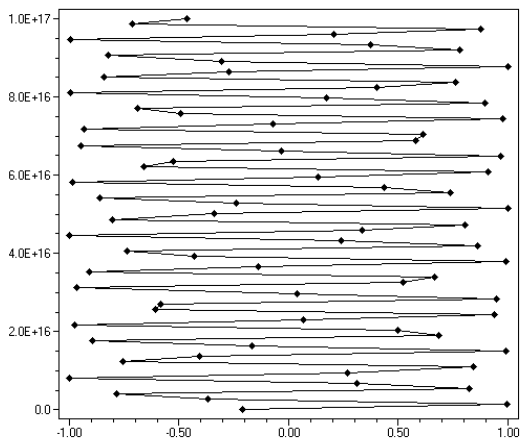

$\mathrm{d}$ theta, phi $=1.35 \times 10^{\wedge} 14$

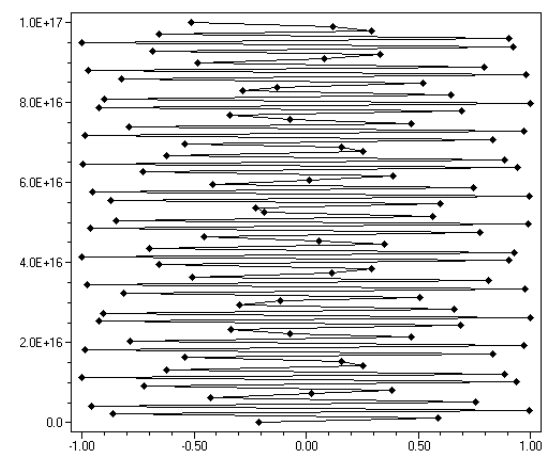

$\mathrm{d}$ theta,phi $=1.0091 \times 10^{\wedge} 15$

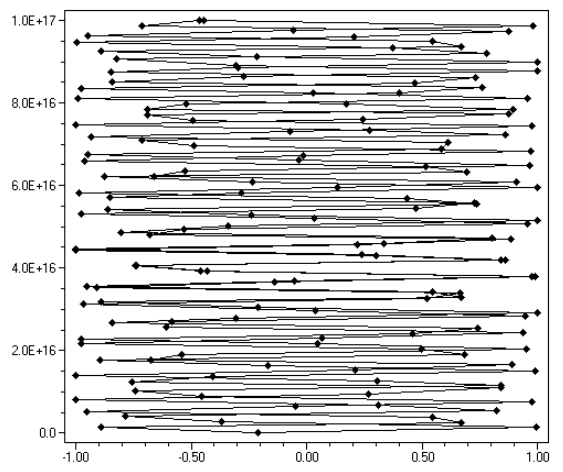

d theta, phi $=$ (overlayed) $1.35 \times$ $10^{\wedge} 15 / 1.2646 \times 10^{\wedge} 15$

Figure 1d. Unique distribution of function values from uneven periods determine different final shapes; a natural egg shape is most commonly observed (Figure 1) (Kirsh, 2011).

Figures 1a to 1c shows criteria for the production of surfaces seem to involve the production of unique inequalities from periodic functions using large regular numbers (e.g. 10^14) that are incommensurate with natural period values (e.g. $1.0 \mathrm{X}$ pi).

Space cannot be expected to be both open and possess tangible surface unless it can be captured to arbitration involving one element with a degree of freedom $\neq 0$ and parameters of that element that can bear a familiarity necessary for interaction with the element degree of freedom $=0$, (i. e. degrees of freedom of a rolling ball rolling ball $=0$ ). Modern science method seems to construct from a perspective that equates natural law with the perception of zero degrees of freedom seen to evolved structures as it defines determined states. The possible existence of mathematically generated closed appearing but open figures resembling nature might be raised to question, apparently it is possible to capture asymmetry to tangible form from discontinuities generated in periodic functions with the use of appropriate input periods that contrast natural periods of functions to demonstrate inequality. The surfaces generated appear to entail an undefined freedom conjectured to result from a bias that produces a unique and uneven assortment, polarity, from ordinarily parity bearing values generated by functions, to produce coherent form; to produce an egg figure values must be uniquely represented. It is possible to speculate that a motion is effected in the graphing situation from the rounding of input angular values acting in concert with design of algorithms used to generate function output values and/or the engineering method of computers. It might be the case that the natural shape of the egg is the product of differences of such very, very slowly changing states that the fixed structures seen in nature are sensitive for their existence on the specifics of digits in sequences distal from wholes values, digits that undergo very slow change and rise to spectacle shape within the surface of approximations rendered from computer oscillators that are engineered from surface bearing natural materials themselves, are ignorant of whole numbers: data also indicate that small $\Delta$ theta $>2.0$ (i.e. 2.1 radians verses $\sim 10^{\wedge} 14$ ) in fields where $10^{\wedge} 17$ stheta $\geq 10^{\wedge} 18$, are equally sufficient to render the same appearing egg shapes.

Human description of mind and tangible substance emanates from a nature that is wish-washy, arbitrates an evolving fabric contained to and containing a recurring volumetric shape/prison and propagated momentum; a suggested order to the exceedingly complex is based on disparities, though between vast quantities, are perceivable and in similar and comparable motion with themselves and the self.

A skewed range, non random, set of sine function values, based on the generation of non periodic data 
employing large period values in graphed equations is postulated to cause the generation of various natural shapes shown in Figures 1a-1c.

Data points are unique rather than periodic. Time is not only indicated to be indecipherably relative, perspective dependent, but ascribable as a second(ary) (excuse the pun) entailment of engagements of familiarity-bearing dimension and form. Temporal connections in evolutionary relations of species based on structure may not be evident. It is additionally feasible that the exact roots of cognition might not be visible (e.g. to itself) by absurdum reduction reasoning if it is inequality that establishes form and substance, the filling of space neither completely random nor exactly orderable. Physical form is interpreted to be the consequence of mass value (meaning number in either scientific or sociological perspective) that is time dependent, neither random nor non random.

If the genetic machinery of the cell along with other facets of its construction might be visualized together to a single frame, a very, very, old and complex spinning machine is entailed that is modulated strictly with respect to angular facets, overwhelming prominence of acute rather than obtuse disparities, familiarity but disparity at the micrometer level, e. g. inequality rather than parity is supposed to govern all relations. It is difficult to determine if a true axis of symmetry exists to surfaces. A parallel example might be found on examination of the uracil molecule that differentiates DNA from RNA; according to structural analysis based on current chemical models uracil possess an axis of symmetry that is not contained to, but crosses the plane of the nearly flat molecule, suggesting the existence of a transparent energy embodied to it; accordingly it has not been found possible to synthesize uracil from its' mirroring half molecules. Description involving the existence of distinct universes can be resolved in terms of the degree of familiarity of agents at the first perspective within their environments; e. g. from a first perspective at the DNA level distal to the first perspective of experimenters, ratios of distances between agents, immediate common causes, can be expected to be far removed from those that define human experience on the earth. It might be expected that the presented existence of form/shape/open-volume capturing ratios are as equally eternal as the universe might be construed to be timeless and eternal such that other states of existence, different with respect to what absolutely defines, is perceivable by, senses, are contemplated to be plausible based on the presented description of processes; 'universe", of itself, entails only the existence of (number and uniqueness)/(force-evolved light/radiation/action-at-a-distance) and disparity of distances for the existence of emerging, self-propagating form, change emerged from within; the existence of different arrays of relative size or number defined processes proceeding historically from what can be construed as a vast contemporary period containing the familiar self and familiarity based perception, conceptually distinct from notions of multiple universes based on ideas involving dualisms and parities, is intuitively perceived to be plausible. If the existence of witnessible shape has no antonym (i.e. witnessible shapelessness) the perplexities of conception or death neither bear in reality the paradox of beginnings and ends if the ability to describe or define, cognitively or physically, emanates from the existence of shape or form rather than time which either also entail; in example, one might hardly see a productivity in communications to continually refer to the existence of the sky in descriptions of life outdoors if it is eternally present.

In order to contrast the nature and role of elastic verses inelastic collisions in cosmological models, a coefficient of restitution for collisions can be described (Wikipedia momentum, 2012):

\section{$\mathrm{Cr}=\mathrm{v} 2-\mathrm{v} 1 / \mathrm{u} 1-\mathrm{u} 2$ Equation 2a}

where $v 1=$ final velocity of first object, $v 2=$ final velocity of second object, $u 1=$ initial velocity of first object, $u 2=$ initial velocity of the second object.

$\mathrm{Cr}=[(\mathrm{v})-(\mathrm{V})] /[\mathrm{v}-\mathrm{V}]$ Equation $2 \mathrm{~b}$

where $\mathrm{Cr}=1$ (Substitution of $\mathrm{u}, \mathrm{v}$ with $\mathrm{v}, \mathrm{V}$ from Equation 1 ), if $v$ and $V$ are assumed to be independent of other elements.

$\mathrm{Cr}=[(\mathrm{vt} 1)-(\mathrm{Vt1})] /[\mathrm{vt2}-\mathrm{Vt} 2]$ Equation 2c

where vt1-Vt1 $\approx$ vt2-Vt2; vt2-vt1 $\approx \mathrm{Vt} 1-\mathrm{Vt} 2 ; \mathrm{Cr} \approx 1$ if it is the case that both $v$ and $V$ are differential victims of $a$ common containing third motion/common cause of events effected at a distance by a variable velocity of light.

\section{$\mathrm{vt} 1=\mathrm{Vt} 1, \mathrm{Cr}=0$ Equation $2 \mathrm{~d}$}

The case of the totally inelastic collision, $\mathrm{Cr}=0$, indicative of motion of attached bodies has no relation to witness pair events and is supposed not to exist; the case $\mathrm{Cr}=1$, i . e. the case of perfectly distinct bodies in the absence of common cause is suggested to mean two universes (see above discussion in section iii) and is supposed not to exist. The case $\mathrm{Cr} \approx 1$, of near elastic collisions is supposed to be the existing case in which an inelastic accumulation from a distance of potential energy with motion is given to be the universal case; e. $g . \mathrm{C}(\mathrm{t}), \mathrm{V}(\mathrm{t})$ are suggested to suffer and exert minute, in ratio, change with respect to potentially vast differentials of mass or number, density, proximity, to describe containing and contained structure (i.e. $M>>m$ ): the world is seen to necessarily bear first order rates of change with respect to time at all places, change in potential energy lagging behind change to kinetic energy. Increasing 
potential accompanying diverse but universally present innate motions results in increasing system diversity, diversity that is both its' own producer and consequent, as an etch-a- sketch drawing in which the drawing area, in the act of acquiring new motion that is the orchestrated product of its own imperceptible relative motion, acquires net diversity to each branch of a growing tree like structure, captures an entire changing drawing area, each point in space, each unique, hence diversity bearing, branch point inheriting new diversity producing potentials that proceed towards identity specific open directions. Attempts to make the drawing hand exemplary for the purposes of understanding human nature, perception, cognition and physiology, in contrast to the example of nature, the provider of funding energy, suffers confused interpretation. The distinction is made, contradicting current models, that communication within associations in space are atemporal in nature and employ $\Delta\left(M^{\wedge} 2\right)$ that acts as both arbitrator and arbitrated; over shared temporal periods of witness engagement, it is a vector of naturally, inexactly, arbitrated directions and magnitudes guided within a force-hierarchy, the nature of causes, mass as number, that engages to produce the 3-dimensional forms that witness both conceptual and physical experience.

In the discussed example, the case of a perfect elastic collision is excluded not because of the case of heat production/ friction, or because of the potential irregularities of surfaces, or heterogeneous nature of entities, but from exclusion of the case $v=0$, the assumption that all objects of the universe are in motion and accumulate potential that is released with a lag over time in a wave like motion intuitively resembling in synthesis combined longitudinal and transverse waves, the extrapolation of the existence of vastly large masses in congruent motion and from which potential energy is constantly acquired, motion at basically constant velocities of objects that are divided from their containing masses by relatively, but not immutable distance. Energy and mass are construed to coexist exclusively, though mass necessarily remains associated with the locus of particular identities, with the increment of energy metabolism, momentum exchange, and not, as contemporarily conceived, within the distance between associating agents.

Within the common cause $\mathrm{M}(1) \mathrm{V}(1)$ entailing consequent(s) $M(2) V(2)$ only atemporal description is possible (the value [Time1-Time(2)]/[Time(impact)] is dimensionless. The assigning of a common time to witness pair associations effects the capture of open space to form via action at a distance whose essense is oblivious to disparities of size and/or mass/number, distance between effecting and effected entities. Neither the separate nor combined events of observation, cognitive reflection might discriminate a unique time to events, a real commonality of distinct events entails not only distinct temporal witness pairs to observation (one pair at a time in the physiological sense), but ratios that are devoid of time, i.e. time $=\mathrm{t}$ excludes the witnessing agents, ad-infinitum so that a universe, itself in motion, is visualized in which accounts of time refer the period following changed momentum after engagements, from the first perspective. This reasoning can be extended to argue that modern distance-time or space-time concepts in actuality relate to dimensionless ratio values and have no bearing on the particulars of events, are confined to a principle shape (Figure 1) as unwitnessible, unreflected propagated energy continually produces witnessible volume.

Though witness is postulated to occur only in the form of witness pairs, if the universe is postulated to be the product of a unique Big Bang like event, the above argument can be extended to imply that relative distances evolved are associated with a unique event in which all that trails in this manner is a chain of associations that, in valid description, is absent of parameters of time at any perspective. A unique event of any kind, such as a big bang birth entails decay of form and release of energy, deconstruction rather than conservation of momentum, energy, form. Human description of witness relations, contained strictly to unique events of observation in witness pairs, entails necessarily and always three temporally/physically distinct agents, the members of the constantly arbitrating witness pair, and the turning potential of the mind providing description; the imagined state of temporal simultaneity is not a feasible condition with which to accurately judge relations, as a concept is a potential destructor of mass/volume and does not exist but to the imagination. It is logically incoherent, as professed in contemporary models, that nature can 'sign and date' 'mail' in the form of light captured from vast distances containing images of the past: what has been contemporily arbitrated from observation has no different type of meaning than that recorded in stories about figures and shapes related from observation of constellations in the night sky.... meaning to encounters is arbitrated involving temporal factors inherent to the nature of the witness process and possess no temporally delayed informational content pertaining to the distant object. Time is inherent strictly to the loci of witness, involves the conceptual, physiological, dynamics of observation consisting of unequal ratio/disparity, disparity with the dynamics of physical/environmental aspects that are place/location associated.

In analogy to the paradox of the ball kicking cow, it is not impossible upon witness to be unable to discern events arising from a proximal common cause, such as acts of aggression or willfully induced motion/ environmental change from events that are further reaching such as inertly arisen disturbances to space, producing change to the environment. In the example of 'weather', one might commonly use the phrase "it decided to rain" as if the elements possessed a mind of their own.

With regards to logic, science, referral to 'god', might 
be taken as an expression of motion possessed to all corners of nature, creator and created. The statements "In God we trust", "so help me God", "as God be my witness" can both refer and not refer simultaneously to an external being, to a nature of and trust in the self as it is the same as inherited to all spaces in an eternal sense, as trust in potential bearing motion that moves in direction with the whole, an eternally replenished product of events themselves able to engender false testimony at the interface of vastly disparate processes and spaces; in the temporal sense 'God' is/can/might be no different to the perception, alive, bearing identical properties, than other beings. Mind-matter paradoxes in the rational construction of reality might reduce to the single statement 'is and is not' in this same sense, projected perception able to occupy a willed attention to attach meaning to the in-betweens occurred within the hidden folds of history, motion that is represented otherwise in the reasoning, as a result of lack of witness, by extrapolated nominal variables; here irony is evidenced in seekings that make an intuitive realization of very complex familiarities, a divide/distance, intinite/finite based relationship of matter and energy, of the material and eternal/conceptual as they refer to unity, God; reality of illusion that resembles experience enough not to be absent of traits distinguishing it from routine sensual experience. The most important in the hierarchy of things that rule life, what both "is and is not", the material and the transcendental as it is sometimes witnessed to the material, are made analogous with visions of a mutable physical, self/other and immutable eternal "concept", respectively, in attention devices thus endowed and able to distort to bear false witness.

Einstein, in his statement "God does not throw dice" (Tomsen,1986) might had expressed intuition, that if the world cannot but be the world, there are immutable criteria that make it so; there exists no other potential criteria other than the rules for simple mathematical operations (i. e. addition, multiplication) as they effect the mind to seek and consider/reconsider causes.

"Einstein originally declared that the distortions of special relativity reflect real changes to the objects being remotely observed, then reconsidered. "(Tilton et. al, 2005 page 5).

Caged between land and sky, the constitutions of political states attempting to construct guidelines for individual freedoms within the foundations of legal processes, establish a free state of nature that declares humans equal to one another, hence conceptually parallel to one another in analogy to parallel lines that do not connect to cause diminished spaces, but are wholly equal and distinct elements able to interact/exchange across a division that is eternally present; courts confined to the same universal processes as the individual, as all universe processes, must reconsider history and experience to make determinations that hopefully reflect the determinations of nature.

It becomes clear that modern social process, though it proceeds with a rationality very much like the rationality employed in the construction of science theory and method, cannot afford the latitude qualified by pending test and falsification possessed to science conjecturing to define and capture processes of matter/energy; processes, confined similarly to the seeking of rational explanation from life experience, must answer not to define objects with abstract logic in order to speculate on causes, but to take all definition from what is evident to observation: contemporary courts, for example, appear stymied to try the ethics of scientific practices that draw description from imagined entities that escape common experience; the scientist, lacking choice or willingness, is never satisfied with description centered on inexactly determinable inequalities. Equality before the law bears a capacity for reconsideration; in the eyes of the scientist, choice as it confronts, is confronted by established natural legalities, is situated somewhere between the rigid mechanics of billiards and an inability to reconcile action and reaction without inferring the existence of a mighty creator in order to account for what it cannot measure, actual potential that gives rise to motion/ change, originates from within. Struggle is evident in the sociological sciences to compete with the exactness of science determination; in legal processes, a vast plurality of incomplete/poorly reflected courtroom decisions resulting in violations of the indigenous rights of citizens from court determined property ownership that does not rule out ownership based on scientific endeavors that alter the characteristics of natural resources and materials that are, other than indigenous to specific regions, in valid description, indigenous to the whole earth. Court room litigation resulting in the application of economic force, physical power that is bound to the free will of individuals rather than natural agents, demonstrates ignorance to the reduction absurdum fact that alternately, the free will of individuals is bound to the inherent and poorly elaborated freedom of natural agents that possess degrees of freedom that are more bound to invisible properties of, though potentially similar, low energy reflective intercourse at vast distances, rather than low energy based observable linear motion of objects. Scientific extrapolations from experience that make space homogenous and infinite deny a period of reconsideration that is subjectively bound to all elements, the observer and observed within the engagement of the thought process to external nature, to all interacting spaces as change is referenced from the witness pair engagement, ubiquitously effecting change to space as intercourses engage receivers, whether physiologically internal or external; the atemporal and simultaneous pair, common cause and intercourse, is the only feature ubiquitous throughout. Though space is filled with discrete, heterogeneous entities, perception processes 
can illegally relocate cause from its rightful ownership, common causes within nature, to the hand of temporally constrained impulse that distorts a true parallel nature of men/woman to one another, can deplete life-times with the application of lines bent by the arbitration capacities of relatively small masses/numbers that have been selfelected to universal status, intersecting on one extreme with the individual finding itself pleasingly invisible within its' construed objective construction of the external, and on the other, with universal processes elaborated as if only undivided, i. e. infinitely divisible, atemporally existing, static divides exist- to apply description effected from concise mathematical elaborations of bends to transmissions. Inappropriate behavior is suggested to be the consequence of an internal physical pathology effected from reasoning that is subject to singular agents of unknown etiology possessing an inappropriate prominence.

Moved to indigenous spaces, laboratories of the same minority power, promoting complex reasoning that is taken, of itself, to be a forceful virtue, professing light mobile to the senses, contains time itself in a mobile state within a perspective that is evolved from a need to account for the infinite that sees light as having something other potentially to do than to bend: in line with thoughts of ancient and medieval times, viewed to contain strict divisions between the pure, the mathematical, truth residing at hard or impossible to breach distances from real life, it is more reasonable to suggest that straight lines do not exist to nature. Scientific language, professing universality, entails a narrower than universal view of human identities that are located disparately in space. Historically evolved advanced mathematical notions of time and space have acquired universal status based on a consumability that discerns a mutual likeness to their creators and is oblivious to an invisible disparity; it seems that objectivity in description has assumed a trait describable as 'the greater the threat of consumption of individual disparities/identity the greater is the considered status of world views'; at the apex are views threatening consumption both of and by their creators. During the course of the history of the theory of relativity Einstein, never having resolved endeavors to his satisfaction, also placed obstruction factors in equations expressing dissent to ideas that the universe was expanding; he had perhaps not considered the possibility of a ratio nature of the invisible, timeless ether as it reflects conceptual disparities born of encounter and contrast, had invented a point of reference, inconsumable but when viewed as a threat to identity itself, separate from those of all parties, including himself, is/maybe/isn't (inclined with historical/physical/ natural/social setting?) universally inconsumable. It might be. It might be supposed that the path of the history of ideas leading to and from Einstein entails facets of an individual threat, engulfment, and autoimmune problems of an accelerating nature such that a simple additive or linear nature of change born from within had become so alien to perception that it was exceedingly difficult to elaborate principle entailing inertial frames of motion to scientific satisfaction.

In argument concerning invention and ownership rights, reasoning concerning the nature of nature, imagined lines that exist necessarily conceptually in parallel are made to converge as if.location and history associated cultural disparities should be straightened employing rationality based insight. As western court determinations are invariably used in applications that traverse non parallel, physical horizons, equatorial barriers, are delivered to the studying mind as if parallel entities, produce a mirage of appearing distances that roll place to place unimpeded by the near spherical shape of the earth, make rectification seeking spectacle of alien rotations. Linear reasoning based on ideal, non-existent in real circumstance, diversity oblivious circular geometry is used to define and market from without centricity, though actually concealed eccentricity, itself the funding potential of diversity upon which the propagation of natural change, change from within, depends.

Almost lunatical behavior is reported by modern corporations; the application of a tax levied on rainwater is reported in world areas where western corporations had inadvertently poisoned water supplies and subsequently invented means to purify resources; applied patent laws are given jurisdiction over genetically modified animals and plants in order to claim right of ownership to resources; especially prominent are cases where introduced genetic elements are found escaped to the wild and patent laws are used to claim ownership of natural resources. Normal cognition potentials endowed to the structuring of conceptual parallels, have been manipulated to bear 'inequalities' inherent to measurable non parallel lines, are dissipative with short lifetimes; the inequality inherent to universal processes has been relocated from the ubiquitous and common to trait specific aspects. Though it can be argued that neither parallel nor perfectly straight lines exist in nature or that curvature of space brings about cognition there are also evidences of phenomenon (e. g. locations and direction of curl of curly hair among populations above and below the equator, differential rotations of water, disparate effects of different types of current on wildlife (Alexandersson, 2002) to suggest that elements distant to populations, the earth, can exert differential rotational/ angular potentials upon nature, hence might influence social/natural intercourses that are both effect and effecter of unaccounted motions to conceptually bound periods of reconsideration as common cause is sought for explanation, to produce aberrant cognitive and/or physical behaviors, especially once disparities have been breached physically. Though the funding motivations of aberrant behavior might be attributed to greed for corporation profit, it is not impossible that an incubating potential originates within confined laboratory experiment, 
concealed within confusion defined by ubiquitously existing chicken/egg paradox as it interfaces the rationality of science method as it arbitrates the means of naturally elaborated processes, to be later expressed by global industries; it is potentially sounder to refer description to shared causes as they effect identity and setting established differential motions. Patent trials establishing ownership based on order of creation/ registration of inventions fail to distinguish correctly equality of whole concepts from parametric inequality: it is the possession of identity itself that is an arbitration product of nature and is the universal source of willfully applied arbitration potentials that have no different etiology from that of natural 'mutation potential'; might the Constitutional Congress had patented the Bill of Rights, though invented by its' constituents, it is meant to honor to mirror the freedoms of the elements of nature, to provide a direction that draws to honor natural and not self-permitted freedoms.

Corporations/societal structures may have created other than insight, mutated/unnaturally bent concepts, mutated courts in addition to mutated genes. It is important to note that causes dominating arbitrations that are later reflected in behavior can theoretically be either visible or invisible, as small as a dime, virus and/or as large the sun, proceed from and/or precede to a weather, constitute a weather that forms the contexts from which judgments ensue. It is not impossible that events and ordering not evident to observation and data can surface from techniques like DNA sequencing or outer space geological observation to offer a new light for new perspectives. The modern processions of social studies are not meant to overtake the movements that have brought about the present, with decision and action that redefines the self with public experiment, to overtake the movements that have brought about the present; existing fluxes are necessarily delivered in steady state association with causes and are not impossibly mutually mutated to later become with regret, self defining, effected of themselves, to be unreflective of the absolutely defining real contiguities and directions of natural history at times when possibilities for more enlightened dialogue might become visible.

A finite universe that is conceived to have a total mass, age, resembles the view of a closed system of concentric planets, one planet, rather than all, sometimes seen alone to bear the judge in legal procedures, forms two accounted prisons, the Universe for the adventure of the philosopher and the Earth and stars for the adventure of the scientist, though it is only the element of motion in a definable ubiquitous elemental form that seduces either; though naturally seen by the senses to bear two faces, the concept of a single faced universe that can be captured from the behavior of pure materials in isolation occupies civilization discourses so tenaciously that manifests bearing basic truths that might be as evident as the necessity for a universe composed of only tangible spaces of thin as well as heavy air are experienced to be heavier in construction, though actually lighter in concept than a described world of dualisms bearing virtually empty gravitational-less space to account for what cannot be visualized to have borders, a world with no end that must be in some manner physically, at least conceptually, round to be contained to a closed fixed loop and not the inequality of difference, in motion itself, seeking, carving open space to all corners, constrained/confined by unwitnessible events and causes in a self rule that witnesses existence. Perhaps regardless of where the world stops and starts, it is strictly the confrontation that contains life and survival, a contest of the physically tangible, appearing closed, with the appearing open freedom of nature cannot be won from a perspective willfully confined to statically imagined walls that in reality move in some quantitatively equal order of range of magnitudes with the self; no matter size or age, nothing can be strictly motionless.

Legal structures in societies that have granted legal freedoms to the individual, such as the United States, contend with struggle to judge ethically the sociological implications and possibilities of advanced technologies; courts accept cases to decide on racial discrimination, rights and privileges of publicly owned educational facilities, citizens and corporations, cases that necessarily bear on the potentials of social and legal process to confront science on the nature and truthfulness of description that is based on evidence from limited witness, to determine and arbitrate aside itself (excuse the pun).

In testament to the efficacy of legal theory, enduring challenge to determine the sides of processes from a position lacking potential witness seems at least to have accumulated its' residues at the interface of legal systems with the individual, economic/political power; an understanding of nature can be witnessed to rest upon the acquired knowledge, wisdom and application from experience with social/legal structures rather than scientific apparatuses.

It becomes clear that the potential of science is itself a determined facet of the determined states that provide the walls used to cage experiments, themselves, becoming self-determined in a manner that can breathe on their own as easily as patented genes can be seeded from their point of sale by the wind, herbicides, toxins carried by water passages to new places. It is just an illusion that attaches a strict mathematical parity to cages and contents, that is found to effect unexpected disharmony occurred from newly assumed rates of motion/ change in new settings. It cannot be assumed that dependable understandings of the relations of mind and matter need to be strictly scientific in nature, nor, with self doubt of crude knowledge from instinct and experience that they are un-capturable by the mind; as innate and visibly as evident as awareness of the potential of the concept to effect either life nurturing or life defeating 
change, only deleterious change might be observed to plans taken rigidly from rigid lines and measures used to assemble ideas about life, matter and the universe.

In converse to the futile mental pursuit of the unconditionally unwitnessible for explanation, a truth of reaction to circumstance is always findable, it should entail a reaction in pursuit of the truth of the circumstance, a circumstance in pursuit of the reaction, whether in the home, science lab, space, or government. If $A$ then $B$ and if $B$ then $A$ entails an absolute truth that always exists to matters involving witnessible events. The tautology from this perspective, bearing mathematical form involving the inequality, involves relations at given times that do not balance; it entails a dependence of the life of the, here described, nature on directed change in the form of reorganization that produces a circumstance in reaction to that preceding it, the mandatory performance of work though none is accomplished in net total on the universe as a whole.

If the free state is to be maintained:

Reaction A ( $\Delta$ time a) $\leftrightarrow$ Reaction B ( $\Delta$ time b)

time $a$, time $b$ are historically emerged and do not bear a mathematical relationship.

Centered on potential and momentum, in converse to relativity theory that elaborates a constant velocity of light, the current model predicts a change effected to potential bound to structure of, for instance, a man walking across a street in relation to that of causes associated with the accomplishment of work. In this sense the "developmental field", within which embryonic processes are proposed to become oriented, can be located to the first perspective of processes that are ubiquitously enslaved to the work of reorientation, reaction from reaction. In empirical example, cancer cells, in a primordial state that is displaced in context with respect to their surroundings, are especially susceptible to death when they are prevented from replicating, likewise cultural traits and behavior linger and become exhausted when they are not active.

Modern society is dominated with problems that can be underlined with respect to the designation "reaction", e.g. chemical reaction, nuclear reaction, auto-immune reaction, heat released by reaction, theory in all disciplines centered on perplexity surrounding paradoxes of action/ reaction, birth, infinity, is here diagnosed to be inundated with activities that can be categorized as directly retransmitted impulse from a struggling nature in the form of 'action' or mimicking rather than reacting to unknown, unwitnessed or correctly identified reactions of external nature. "reaction" that is birthed from potential accrued from with-in.

It was found possible to graph an exact 3-D replica of an egg with a simple equation that reflects the discussed conceptual and philosophical difficulties; graphing considerations employ a variable for the velocity of light, a common state time attributed to the engagement of witnesses rather than an ether through which light is transmitted, a line of physical motion bound to the first perspective that originates as received potential and physical momentum that births the same, and an induced displacement of angles used to generate values of sine and cosine functions that compromise ideal periodicities, reveal patterns that arise from within vast numerical ranges and are neither random nor non-random: the general case, based on reasoning centered on circular symmetries is dismissed for explanation, it alludes to action, creation, rather than reaction (i.e. reaction to a sinusoidal period of the circle, with a period defeating distortion that captures change that is other than random or non-random) and is based on experience that is attached for explanation to a reality that is unconditionally beyond reach. Proposed here is a special case that can account for all events in tangible form with the imposition of criteria of conditional witnessibility that is location/place associated, involving either or un-witnessible containing elements of the same root construction or conditional accessibility of same constructed elements to human witness.

The energy of conceptualization, based on this result has here been relocated in supposition to replace the notion of the ether and reduce it in description to the, though unwitnessible, lengths and volumes of unreflected emitted light radiation as momentum-energy states that are propagated in a genetic-temporal fashion and are place/location specific, are constituted of numerical inequalities in a universe in which all components are not only in relative motion with respect one another, but in proportions that are commensurate with the natural motions that consume the first perspective/human sensual experience. In interpretation, concept evidences substance and substance evidences concept in a necessarily mutual existence; either are bound to the atemporal forms alluded to in the presented 3-D graphs in which size and process fitting/compatibility is genetically modulated to be place-in-space/line-of-emergence dependent. The simple forms created are suggested to represent maximum energy lifetimes as they are evolved from straight, hence maximally open, lines; are conjectured to be witnessible under certain circumstances (e.g. the biological egg), to comprise language and experience such that the evolution and single usage of a single concept, i.e. the word "and", entails a vast number of occurrences, positions/orientations, energies and motions that evidence it.

Interpretation referring to the nature of the imagination in the creation of the plot in literature, the natures of prose and science, defining historical attributes that are so difficultly approached analytically or ignored, are typically brought to light in disputes about the nature of mimesis, culture as mimesis, in which parallels have been drawn between the essence of science and literature (Mchoul, 2009, Dukor,2009, Ivic,2009) within discourses that question their relation to perception and 
experience, hence, nature; the naturalization of epistemology is a central issue in philosophy. It would seem proper to address a role of the theme of "man verse nature" as it is inherent to scientific activity, momentum and encounter entail propagation, the inheritance of characteristics that is inherent to all processes but not so obvious with respect to the topic of creative literature. When the nature of thought, the imagination, mimesis poesis, is raised to question, though more readily apparent as actors in a plot confront each other, a "verses" quality to the question of mimesis and nature becomes obscure when it asked what the prose or poem verses (excuse the pun). Perhaps it is true that men are always in confrontation with nature whether they are on one hand identical with it or on the other not identical with it, raising to question whether nature and/or men, act or react, create or mimic in response to a received universe that cannot be contained without inclusion of the transcendental object. In a discussion of the poet Sri Aurobindo and Albert Einstein (Kumar, 2012), a view of matter or substance as the object, energy as the transcendental object is expressed, making matter in analogy to the shadow of the transcendental. With regards to the question of "verses", as a reflection necessarily moves with the object it reflects, it is plausible to imagine that within the essence of nature that is received/confronted, the object and its' reflection are not equal or in equal motion either within a nature that is viewed separate from the self or identical to it; the transcendental object is here attached to the arbitration of path, establishes the thought, concept, chain of words attached to the vision, from which intercourses ensue.

The question of naturalization becomes redundant; either apparent in accounts of the confrontation, or assumed in description if change-from within, e.g. reaction, is held to account for all and is contained not as creation, but to be creative, in likeness only to causes from which characteristics are inherited by witness association; reaction is but an unequal reflection of causes in the sense that motion bearing form/shape is the product of arbitration that is a property of all states, the physical and conceptual self and their constituents. The law of motion proclaiming that for each and every action there is an equal and opposite reaction finds no applicable use to define nature as it is experienced by reasoning that is attached to the first perspective of the senses; all experience can only be attached as it is evolved, exclusively from the first perspective. It is not difficult to see how the theory of relativity is so broadly appealing in its' handsomely round but incomplete condition that divorces unfathomably high numbers bound to unwitnessible vast physical dimensions with the ascription of the apprehendable and more seducible single allocation 'infinite universe bearing "mass" operating in a proximity dependent manner to effect weight or force, but to consider the prospect of action at a distance, rule of controlling elements existing under absolutely unwitnessible circumstances; better miniscule electrons or photons, though likewise unwitnessible, beyond approach with laboratory weighing scales, they are contained to familiar environments within proximal spaces, within any of the rooms and boxes in the laboratory.

Prominently absent from interpretation is a proper distinction between parameter and concept, the existence of atoms and molecules evidenced from experiment and interpretation can be seen as but parametric facets of an inconceivably old process of encounter of identity-bearing spaces at the range of all possible distances. Within the proposed universal existence of the power of arbitration possessed to all spaces it is ironic that the prospect of action-at-a-distance is so anxiety provoking, the conceived arbitration property of spaces also entails the existence of proximal modulation of events, of the individual over circumstance; though seeking to inhabit the stars, it is perhaps historical events and behaviors that have created a path to a state of affairs in which temporal rather than physical distance is the perceived unconquerable topic.

As they reflect natural states in which visible expression of change, i.e. motion or the release of kinetic energy that follows with a temporal lag changes to the potential of volumes, the assignment of determined states in scientific methods is potentially able to alter/ mutate language, conceptual structures, courts, and witnessed social, political, economic processes via the creation of obstructions to the accomplishment, by either men or materials, of the naturally arisen free state.

In summary, the light of day of human society and the earth ecosystem is evidenced to be threaten by failed reactive application to matters of nature with periodicity stripping wisdoms, acquired from the paths of learning, upon idealistic-mathematical concepts bearing ideas of infinity and zero, circular interpretations; failed judgment has resulted in an evolved and propagated complicity with a poor weather, the willful and faithful transmission of, received impulse, action other than reaction, to consequent a pathology bearing an etiology that can be viewed to be not so seriously complex, involving heat, energy, a struggle for integrity, and the unwanted propagation of potential ensued from the invasion of indigenous and sovereign spaces by unknown or undetermined entities. A conceptual difficulty with numbers, fear of a perceived endlessness, infinity, zero, inclination towards statistical analysis that strips identity and uniqueness from description, is suggested to reside at the source of struggles. In imagined example, a light weight object falling into witness range, possibly perceived instinctually to have universal importance, other than reacting to free it from obstruction, witnesses might had, as a consequence of fear (of the infinite), elicited no (zero) response, resulting in a historically propagated population in which the individual captures the world rationally in terms of zero and infinity.

From the perspective of question and experiment 
concerning the forces that hold matter together, universe structure is taken to resemble somewhat flexible/ malleable form and functioning that is time and place dependent within an ever-emerging weave of vast proportion of the same. If it is not creation-entailing action, but arbitration-entailing reaction that entails truth, knowledge and substance, if a cure is sought, for example to the problems of global warming, greenhouse gasses, trespasses of nuclear war, or auto-immune disease, perhaps the phrase 'men of action' might be quietly rephrased to 'men of reaction' to indicate the origin of problems and a conceptual orientation conducive to their resolution.

Michael Foucault (1977), elaborating social behavior and penal history in terms of the containing power of the discourse, establishes as a universal a 'prison' that is ever present, change that is confined to power associations of the discourse: in this presentation it is additionally asserted that the existence of witnessible substance is conditional on the existence of a containing though open, surface that is effected, as meaning is effected in discourse, via familiarity, in either case on a familiarity of becoming change to the history and parameters of unwitnessible energy (i.e. the concept) and matter (physical change effected from work to the environment).

\section{Conclusion}

For the purpose of sociological application, philosophical discussion is ensued concerning the frustration to extrapolate to determine a real nature of objects from a distance with experiment that probes in the absence of direct witness. It is concluded that processes referred and focused with respect to a logical opposite meaning of the qualifiers "determined", as it references defined states and entities in science theory, and "free", as it references the equality of individuals, can provide a natural and selfevident criteria for description of processes. It is especially noted that universal rates of change with time, expected to be relatively linear are experienced in perceptually commensurable and interpretable sizes and proportions at accessible witness points regardless of location and nature of causes, challenge philosophical rather than scientific capabilities.

It is plausible that mourning of loss on a global level of an unknown simultaneous symbol and object, transcendental and unencountered material form has been overtaking thought and behavior in historical scales in advance of awareness, in sublimation of absent aware perceptual/sensual experience and appropriate reaction, to effect the association of form and function together in pursuits of the unknown, to cause the realization of a deeper loss than is actually occurred. Better footing on such a dark slope might entail new philosophical reasoning and interpretation of place in order to maintain focus.

Valid understanding entails, beyond the application of numerical balances/equalities, naturally occurred and perceptually capable differences involving vast numbers of vastnesses.

Cognition, construed to ensue in advance of standard scales of measurement, from the senses by contrast, might only proceed towards the successful resolution of problems legitimately that same way with the continued employment of inequalities to render disparities from the outset in advance to the rendering of concepts, parities to discourses, otherwise to potentially threaten innate spaces reserved to reflections of a spiritual nature involving strictly the free state. The containment of nature to dimensionless form entails that the dimensions of containers and their contents may bear no rigid or absolute relations; containing truth, referring to number/ mass for its' descriptive elaboration, is none-the-less itself not a function of number/mass.

Modern science studies employing methodological scientific apparatuses are able to effect from the occurrences of a nature that contemplates within the processions of becoming form, reduced conceptual and material freedom; it is advanced here that sound conceptual understanding precludes the inefficient use of time and resources, potential damage to man and nature from pursuits attempting to associate together analytically with scientific method, functioning with form, conceptual meaning involving a simultaneity of motion and form that are logically discrete from each other, though evolved mutually from the intellect by either experience, imagination and/or induction the imagined character of their combined existence contradicts a real nature to the perceiving of objects; concepts, belonging to the set of concepts, can accommodate universal proportions only of distance/volume that contains solely itself, constitutes both itself and common objects (such as the real egg, a rock, a dog) that are bound simultaneously to direct perception and to the transcendental; other than the arbitrated time-bearing reactions that compose material history, it is more reasonably construed that the closest and hence most powerful relative to the real contours and surfaces of life, defining familiarities in contexts and hence arbitrations and behavior at all perspectives for all evolved spaces, objects and entities, is ironically a transparent, but distance and form bearing, non-material transcendental; similarity bearing physical substance some of the time, ironically defines all of the time strictly and inclusively the substance of experience, accounting for all, the perceiver, the perceived, and the means of navigating the world.

\section{REFERENCES}

Alexandersson $O$ (2002). Living water: Viktor Schauberger and the secrets of natural energy, ISBN0855001127,Turnstone Press (Wellingborough, Northamptonshire). 
Angelou M (1969). I know why the Caged Bird Sings, Random House< New York

Dukor M (2009). Theistic panpsychic naturalized epistemology: the scientific philosophy of Africanity and einsteinism. September, http://www.academicjournals.org/PPR/PDF/Pdf2009/September/DUK OR.pdf Philos. Pap. Rev. 1(3):034-043

Einstein A (1905). On a Heuristic Point of View aboutthe Creation and Conversion of Light? trans by D. Terr Haar Ann. Physik 17, 132 in The Old Quantum Theory Pergamon Press, 1967. http://users.physik.fu-berlin.de/ kleinert/files/eins_lq.pdf.

Fairbanks DJ (2010). Relics of Eden, Prometheus Books, Amherst, N. Y.

Feyerabend P (1975). How To Defend Society Against Science, Radica Philosophy no. 11. http://www.galilean-library.org/manuscript.php? postid $=43842$.

Foucault M (1977). Disciple and Punishment :The Birth of the Prison, Alan Sheridan trans, Vintage Books New York.

Giami A (2001). Counter-transference in social research: beyond George Devereux, Papers in Social Research Methods - Qualitative Series, no 7, [ed MW Bauer].London School of Economics, Methodology Institute]. http://www2.Ise.ac.uk/methodology/pdf/ qualpapers/giami-counter-transference2000a.pdf

Gould SJ (1981). The Mismeasure of Man, W. W Norton and Company, Revised and Expanded New York.

Hesse M, Brown S, Collinson D, Wilkinson R (1996). Biographical dictionary of twentieth-century philosophers. London, Routledge. pps. 336-337.

Hutcheon P, Duffy P, Kuhn (1995). Evolution of Science, Brock Rev. 4(1/2):28-37.

Ingold T (1993). "The Temporality of the Landscape." World Archaeology 25(2):24-174.

Ivic S (2009). Ricoeur's narrative theory applied to science, Philos. Pap. Rev. 1(3):044-051 september,.http://www.academicjournals.org/ ppr/pdf/pdf2009/september/ivic.pdf.

Kirsh ME (2011). Evolution at the Surface of Euclid: Elements of a Long Infinity in Motion Along Space, http://ssrn.com/abstract=1575622. Int. J. Arts Sci. 4(2):71-96.
Kirsh ME (2012). Science, the Virtual and the Actual: A Real Stand-off, http://MarvinKirsh.cgpublishers.com. Int J. Sci. Society 3(3):159-169.

Kumar N (2012). Sri Aurobindo and Einstein's theory of relativity, June. http://www.academicjournals.org/PPR/PDF/pdf2012/June/Kumar.pdf. Philos. Pap. Rev. 3(1):1-10.

Mchoul A (2009). The being of culture: beyond representation. November. $\quad$ http://www.academicjournals.org/PPR/abstracts/ abstracts/abstracts2009/November/McHoul.htm. Philos. Pap. Rev. 1(5):067-073.

Morrow GR (transl) (1970). Proclus a Commentary on the First Book of Euclid's Elements, Princeton University Press p.217.

Tilton HB, Smarandache F (eds) (2005). Todays Take on Einsteins' Relativity, PROCEEDINGS OF THE CONFERENCE OF 18 FEB Page5. http://webcache. googleusercontent. com/search?q=cache:YLBCpC8TligJ:fs. gallup. unm. edu/ProceedingsTucson. pdf+Einstein+pima+community+college \& $\mathrm{hl}=\mathrm{en} \& \mathrm{gl}=\mathrm{us}$.

Thomsen DE (1986). As Gods' Dice Fall,Yurica Report, New Intelligence Analysis Science News. http://www. yuricareport. com/Science/As Gods Dice Fall_Was Einstein Wrong. html.

Wells S (2007). Deep Ancestry, National geographic Society, Wash D.

Wikipedia (2012). Gregor Mendel, http://en. wikipedia. org/wiki/Gregor Mendel.

Wikipedia, Momentum (2012). http://en.wikipedia.org/wiki/Momentum\# Conservation of linear momentum. 